\title{
Necessity, Possibility and Determinism in Stoic Thought
}

Vanessa de Harven, UMass Amherst

\section{Introduction}

Necessity and possibility in Stoic thought run deep, through logic, physics and ethics together. There is a wealth of scholarship just on Stoic responses to Diodorus Cronus' Master Argument that everything possible either is or will be true, revealing the Stoics' sophisticated propositional logic and modal theory. Likewise, scholars have long mined the Stoics' innovative theory of causation and their unique commitment to an everlasting recurrence of the cosmos, elucidating the scope of necessity and possibility in Stoic physics. And, perhaps most famously, the vexed relationship between determinism and responsibility testifies to another vein of modality running through Stoic ethics. This paper will argue that underwriting the Stoics' moves in all these areas is a distinction between logical, metaphysical and what I will call providential necessity and possibility.

Complicating matters, the Stoics are known to embrace apparent paradox, a trace of Eleatic influence through the Megarians. ${ }^{1}$ It will become apparent as we proceed, that understanding Stoic thought is doubly challenging: in addition to the exegetical and interpretive challenge of dealing with ancient, self-consciously paradoxical views, there is also, inextricably, the basic reconstruction of Stoic views through often hostile lenses. The textual evidence of Stoic thought is fragmentary, scant and subject to widespread interpretive debate. Thus the method of this essay will be to undertake a close textual analysis of a single piece of testimony from Diogenes Laertius on Stoic modality, bringing other passages to bear as needed. ${ }^{2}$ I will show that we can find these three senses of necessary and possible in Diogenes' report, and that the Stoics can exploit this systematic ambiguity to embrace the air of paradox while crafting a unique compatibilism in their ethics, making room for counterfactual truth in a pre-determined physics, and upholding bivalence amid genuinely possible futures. ${ }^{3}$

\footnotetext{
${ }^{1}$ To name just a few: only bodies exist, but not everything that is Something exists (Alexander, In Ar. Top. 301,19-25 (27B); Democritus' cone split in half yields surfaces that are unequal, and neither equal nor unequal (Plutarch, Comm. not. 1079E (50C5); we consist of a determinate number of parts (head, trunk and limbs) and yet no determinate number of parts (in virtue of infinite divisibility of their continuum physics) (Plutarch, Comm. not. 1079B-D (50C3) 2 I have chosen Diogenes Laërtius' (hereon DL) testimony at 7.75 for its completeness and greater detail over Boethius, In Ar. De interp. 234.27-235.3, which only gives the first three definitions and is otherwise in general agreement with DL

${ }^{3}$ I am going to operate on the hypothesis that it is legitimate to speak of the Stoics as a whole in reference to orthodox views that unify the school. I do not thereby deny that there was internal debate or that successive heads of school and other individual Stoics left their mark on Stoic doctrine. Rather, I take there to be core doctrine against which, as an agreed-upon background, there were more fine-grained internal debates. In this case, the relevant orthodoxy is the recognition of these three senses of necessity and possibility (Cleanthes and Chrysippus on the Master Argument notwithstanding)
} 
By logically necessary, I will mean what is true a priori (e.g., If it is day, it is day). ${ }^{4}$ By metaphysically necessary I will mean what is true a posteriori, as a function of the active principle

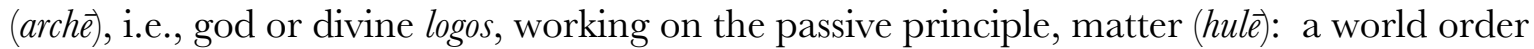
according to certain metaphysical principles and natures. ${ }^{5}$ By providentially necessary I will still mean what is true a posteriori as a function of the divine active principle (god), but this time god conceived as the immanent chain of efficient causes, acting through the natures and principles established as metaphysically necessary, to bring about the same world order time and time again. The Stoics are committed to an everlasting recurrence of the cosmos, punctuated by periods of conflagration when the world turns into fire and then starts over. Crucially, however, while the laws of nature are necessary, the fated (or determined) chain of causes is not. So what is providentially necessary is not defined in terms of what will be, but only in terms of what is or has been. A particular event only becomes providentially necessary once it is underway or in the past; until then the future remains providentially contingent - even though bivalence holds. Hence for the Stoics there are future truths that are not necessary. ${ }^{6}$

Corresponding to these three senses of necessity, according to my reading, what is providentially possible is what the circumstances allow; this will include ordinary circumstances like not being in jail so it is possible to go to the agora, and what one might characterize as technical circumstances, like being in future, so it is not yet settled, given the unwinding of the rope of fate so far. ${ }^{7}$ Metaphysically possible is what the metaphysical principles and natures allow regardless of the external circumstances; and logically possible is what is not self-contradictory. So what is providentially possible is a subset of what is metaphysically possible, which is itself a subset of the logically possible. I hope this suffices as a preliminary account of the three senses of necessity and possibility I have in mind. I will fill in the details of this picture in the next section, as I argue from the textual evidence.

\section{Textual Evidence}

As I have alluded, at the heart of the Stoic theory of modality is a strict commitment to bivalence, even for future contingents. Naturally, this commitment to both future truth and contingency has often been thought paradoxical, and the hostile commentators from whom we get much of our scant testimony make the most of it. So we will begin with testimony from Diogenes Laertius, a neutral and generally reliable (if sometimes superficial) doxographer. I will provide the entire passage A here, then undertake a close reading of the numbered segments.

A. (1) Further, there are those [axiōmata] on the one hand that are possible (dunata), as well as those on the other that are impossible (adunata). And there are those on the one hand that are necessary (anankaia), and those on the other that are not necessary (ouk anankaia). (2) Now, possible (dunaton) is what (a) admits of being true (to epidektikon tou alêthes einai), (b) not being opposed externally (tōn ektos mé enantioumenōn) in being true, e.g., "Diocles is alive." (3) Impossible (adunaton) is that which (a) does not admit of being true, <or (b) what does admit of being true but is opposed by things

\footnotetext{
${ }^{4}$ I have avoided characterizing logical truths as analytic because I am do not think the analytic/synthetic distinction is entirely applicable; see Martha Kneale's 1938 "Logical and Metaphysical Necessity" for an effort to apply this distinction to Stoic modality

${ }^{5}$ Kripke 1972

${ }^{6}$ As well as false futures that are not impossible; see Cicero, passage B, below

${ }^{7}$ For the image of the rope see Cicero, Div. 1.127 (55O), Gellius 7.2
} 
external to it from being true>, e.g., "Earth flies;" and (4) necessary (anankaion) is (a) that which being true, does not admit of being false, or (b) what on the one hand does admit of being false but is opposed by things external to it from being false, e.g., "Virtue benefits;" and (5) not necessary is that which both is true and can be false, being contradicted by nothing external, e.g., "Dion is walking."8

Note first, from A1, that the bearers of modal properties are strictly speaking axiomata, ${ }^{9}$ which we can translate loosely as propositions; they are incorporeal entities distinct from the corporeal words uttered and world spoken about, a species of what the Stoics call lekta, or sayables, which also include questions, imperative, oaths, et al. ${ }^{10}$ Axiomata are introduced by the Stoics to be the bearers of truth value, enter logical relations, and ground causal analysis, as well as to be shared in communication and to stand as the objects of our assent as rational agents. The Stoics' correspondence theory of truth is well attested, so it will be uncontroversial to take the modal properties of propositions as evidence about what is necessary and possible in the world itself. ${ }^{11}$ Note, too, that I take it as given that the Stoics' modal notions are interdefinable in the customary way, with necessarily contradicting possibly not, and so on. ${ }^{12}$ I will thus move freely between speaking of what is possible and not necessary, impossible and necessarily not.

Another interpretive question about this passage concerns the connection between (2a) and (2b): whether they are two distinct conditions for possibility, or whether (2b) merely explains (2a). Michael Frede has argued and most have agreed that the genitive absolute not being contradicted externally in being true should be read as giving further conditions for possibility, rather than as an explanation of what it means to admit of truth. ${ }^{13}$ I will also take this as given, so that the possible is what both (a) admits of truth (can be true) and (b) isn't opposed, or hindered, externally.

But what does it mean to be opposed externally, and what does that tell us about admitting of truth? Here too there is some debate, and for my purposes, an opportunity for some added clarity on what the relevant externals are. Susanne Bobzien, embracing the conjunctive reading, has suggested that admitting of truth is a matter of being internally consistent, i.e., not selfcontradictory; the Stoics are concerned to exclude items like round squares. ${ }^{14}$ Thus the relevant externals are those things external to the logical subject of the axioma; the first part of the definition (2a) embraces Philo's modal definition of the possible: that which is capable of being true, by the proposition's own nature, i.e., intrinsically or internally as a matter of logical consistency. ${ }^{15}$ I agree with this reading and take what admits of truth (2a) to capture the Stoic

\footnotetext{
87.75 (38D); parenthetical citations like 38D refer to the chapter and order of passage in Long \& Sedley 1987, hereon LS; unless otherwise noted, translations are LS with modifications

9 Thus, as Bobzien 2003: 117 puts it, not a logic of modal propositions but of non-modalized propositions insofar as they themselves are possible, necessary, etc.

${ }^{10}$ DL 7.66-7

${ }^{11}$ DL 7.65 (34A); for arguments to this effect see D. Frede1990, Bobzien 1993

12 This is largely agreed but not settled. See Paolo Crivelli's thorough accounting of the current state of this debate in the Complements to Mignucci 1978 in Brunschwig 2006

${ }_{13}$ M. Frede 1974. NB: this debate is related to the question of interdefinability: on the conjunctive interpretation of the genitive absolute the necessary and the impossible are disjunctive definitions, while possible and not necessary are conjunctive, as required for interdefinability. Cf. Mignucci 1987, Sorabji 1980

14 1993: 76-7; Hankinson 1999 concurs on this point

${ }_{15}$ Boethius 234.10-21: possibile esse, quod natura propria enuntiationis suscipiat veritatem, ut cum dico me hodie esse Theocriti Bucolica relecturum
} 
notion of what is logically possible, their widest modal notion and minimal constraint on contingency. However, using the external opposition of (2b) as a contrast case to understand the possibility of (2a) as internal to the concept, says nothing yet about what it means to be hindered externally.

Bobzien and most other commentators have understood external hindrances, quite sensibly, as circumstantial barriers to something's happening; "ordinary, physical hindrances: for example, a storm or a wall or chains that prevent you from getting somewhere; the surrounding ocean that prevents some wood from burning."16 So Bobzien defines the possible as (a) what is logically possible, and (b) is not in fact prevented by the circumstances from happening. If wood is not (or will not be) at the bottom of the sea, then it is possible for it to burn. If you do not spend the rest of your life in chains, it will be possible for you to go to the agora.

However, one might worry, as Margaret Reesor does that such a reading conflicts with the well-attested Stoic response to Diodorus Cronus' Master Argument, namely their commitment to there being something possible that neither is nor will be. ${ }^{17}$ Briefly, the Master Argument consists of three mutually inconsistent premises designed to restrict the possible to what is or will be, i.e., to the actual. They are that: 1) Every past truth is necessary; 2) An impossible cannot follow from a possible; and 3) There is something possible that neither is nor will be. ${ }^{18}$ Diodorus is committed to the first two in exclusion of the third, so that what is possible is what is actual. Although Cleanthes and Chrysippus disagree about whether the first or the second premise is to be rejected, the Stoics are in any case committed to the truth of the third. So here again we see the Stoic commitment to future truth and contingency together. Reesor's worry, as I understand it, is that casting external hindrances in terms of opportunity conflicts with the Stoic commitment to things that are in fact hindered being nonetheless possible; the conflict arises because ex hypothesi they won't take place, so they will be hindered, and thus will not have the opportunity. Likewise, Reesor worries that the following testimony from Cicero about a jewel that is in fact hindered but nonetheless possible to be broken, suggests that possibility is not restricted to opportunity.

B. For he [Diodorus] says that only that is possible which either is true or will be true; that whatever will be is necessary; and that whatever will not be is impossible. You [Chrysippus] say that even things that will not be are possible. For example, that this jewel be broken, even if that will never be the case. And you say that it had not been necessary that Cypselus should rule in Corinth, even though the oracle of Apollo had foretold it a thousand years earlier. But if you are going to endorse these divine predictions you will also hold things falsely said about the future to be in such a class that they cannot happen, so that if it be said that Scipio will take Carthage, and if that is truly said about the future and it will be thus, you must say that it is necessary. And that is precisely Diodorus' anti-Stoic view. ${ }^{19}$

\footnotetext{
16 1999: 119, also 1993: 77

17 1965: 292, n. 17

18 Epictetus, Diss. 2.19.1-5 (38A). There has been a tremendous amount of scholarship devoted just to reconstructing the argument so that any two premises entail the contrary of the third; see for example, Barreau 1978, Denyer 1981, Kneale 1938, and Prior 1955 (who argues we can find Lewis' S4 system in Diodorus). We can bypass these issues because it is uncontroversial that the Stoics agreed in accepting the third premise of the argument, i.e., in holding that there is a possible that neither is nor will be. Therefore I will also largely bypass the details of Chrysippus' and Cleanthes' diverging strategies with respect to the other two premises.

${ }^{19}$ De Fato 13 (38E3)
} 
Now, one might yet reply that the Stoic commitment to the third premise of the Master Argument is compatible with the reading that external circumstances must provide the opportunity for something to take place if it is to be considered possible, even if it will not take place as a matter of fact. One could maintain that as a matter of fate (and thus fact) a certain piece of wood will not burn, but that what makes it nonetheless possible is that it is not (or will not be) at the bottom of the sea; and that what makes it possible that the jewel will break is that someone has the opportunity to break it, and can thus be praised for not doing so. ${ }^{20}$ What I would like to say at this juncture is that, while it is true that moral responsibility requires opportunity (i.e., that you cannot be praised for not breaking a jewel if you were nowhere near it), this cannot be the whole story of possibility in Stoic thought.

Indeed, I think it likely that Zeno's agreement with Philo extends beyond logical possibility as conceptual coherence to possibility as metaphysical coherence, i.e., from the first part of the definition (2a) to the second (2b). Philonian possibility is described as follows by Alexander of Aphrodisias.

C. "That which is said in accordance with the bare fitness of the substrate (to kata psilèn legomenon tên epitèdeiotèta tou hupokeimenou), even when having been prevented (kekōlumenon) from coming about by some necessary external factor." Accordingly, he said that it was possible for chaff in atomic dissolution to be burnt, and likewise chaff at the bottom of the sea, while it was there, even though being prevented of necessity by its surroundings. ${ }^{21}$

According to this passage it is possible for wood (or chaff) at the bottom of the sea to burn because it is of a nature to burn, regardless of whether circumstances prevent its burning. Wood is combustible according to its bare fitness or suitability to burn, i.e., according to its intrinsic nature, so it is not just logically but metaphysically coherent to call it combustible even when surrounded by water (in a way that it would not be to call water itself or iron combustible). Similarly, a shell at the bottom of the sea is perceptible, even if circumstances prevent its being perceived. To locate possibility in the bare fitness of a subject is thus to move away from possibility as opportunity and toward possibility as intrinsic capacity, placing it in the nature inherent to the entity. The issue of how far the Stoics agree with Philo is fraught because of conflicting evidence that points both ways. ${ }^{22}$ My suggestion is that the Stoics agree with Philo in locating possibility in something's bare fitness, or intrinsic nature; but disagree with Philo insofar as they also recognize possibility as opportunity. This would explain testimony in both directions, and solve what Bobzien calls the Philonian Paradox, that possibility defined in terms of bare fitness leaves no reasonable room for responsibility. ${ }^{23}$

Reesor has argued persuasively that possibility for the Stoics is "found in the principal cause (e.g., breakable), which was a quality inseparable from its substratum (e.g., gem) and the cause of a predicate (e.g., is broken) which may or may not be realized; and a possible event is one in which the predicate is derived from the principal cause but which may or may not be

${ }^{20}$ As Sorabji 1980: 272 insists, and LS: 235 agree

21 Alexander, In Ar. An. Pr. 184.7-9 (38B2); cf. Sharples 1983

22 Both in the ancient evidence: Plut., St. Rep. 1055E (for), Boethius 234 (against); and in contemporary commentators: Bochenski 1951: 87, Mates 1953: 41, Rist 1969: 115 (for); Bobzien 1983: 75-76, Kneale 1962: $122-$ 123, Sorabji 1980: 271 (against)

23 1993: 75 
realized (e.g., The gem is broken)." 24 The principal cause is what I have been calling the intrinsic capacity, or nature inherent to the entity. A gem is of a nature to be broken, whether it is broken or not, so that opportunity is not the salient issue but rather what things are true in virtue of (what predicates can be derived from) the principal cause or nature of the entity, i.e., what it can do given the kind of thing that it is. ${ }^{25}$ Another well-known example of a principal (alternatively, perfect or complete) cause is the shape of a cylinder. ${ }^{26}$ Although an external (alternatively, initiating or auxiliary) cause may be required to set a cylinder in motion, say, someone pushing it, the responsibility and complete explanation for that motion lies in the shape of the cylinder. Crucially, this intrinsic capacity is where the Stoics locate moral responsibility - someone may have pushed the cylinder, but it rolls because of its shape; analogously, a thief may be pushed to steal by seeing a jewel that can be taken, but a thief steals because of character.

Reesor argues also that the Stoics recognized two distinct senses of fate: that of the internal, principal cause (the nature with which you are born and its habituated states developed in reaction to the environment, i.e., the nurture it receives), and that of the series of external, initiating causes, i.e., the sequence of events to which principal causes react. The unwinding of the rope of fate is thus the interaction of external causes with internal natures. ${ }^{27}$ So, for Reesor, a possible event is a predicate derivable from the principal cause, which may or may not be realized due to external circumstances. Or, as I would prefer to put it, what is possible is what something's nature (in the first sense of fate) allows, independent of what in fact goes on once fate in the second sense, as the chain of external causes, is in motion. Thus a piece of wood at the bottom of the sea is combustible because the predicate is burnt resides in the principal cause (i.e., it is of a nature to burn), even if external causes prevent that predicate from becoming true of it. By locating possibility in the principal cause, internally, Reesor rightly separates possibility from opportunity.

Robert Hankinson also recognizes something like this in the Stoics, two distinct types of modality he calls species possibility and actual possibility. Species possibility corresponds to what is "possibly applicable to an individual of natural kind $\mathrm{K}$ just in case K's can, other things being equal, be P's;" while actual possibility is defined by what actually obtaining circumstances do not prevent; he adds "if this is right, it is false to say that the only type of possibility available to the Stoics is epistemic."28 My purpose in limning this debate in the literature over possibility as

\footnotetext{
24 1965: 296; see also Reesor 1978 and Stough 1978 in the same spirit

${ }^{25}$ I prefer not to speak in terms of predicates (kategoremata), which represent an interpretive challenge of their own that we can put aside without damage to the present thesis. Predicates are considered incomplete lekta (sayables) and they figure prominently in the Stoic account of causation, in the role of effects. D. Frede argues that lekta are the laws of nature themselves; and Reesor in effect makes the same point; cf. also Striker 1987. I agree that the Stoic theory of modality is concerned to underwrite counterfactual truths about nature, but I disagree that the lekta are the laws themselves, or that lekta should be cast as events, facts or states of affairs in any case.

26 e.g., Cicero, De Fato 42 (62C5)

27 The image of the rope unwinding is not entirely felicitous since the idea is more like the winding of a rope with internal and external causes coming together to intertwine; perhaps we might now prefer the image of a zipper ${ }^{28}$ 1999: 528. Given more space, I would have liked to engage with these and other scholars whose analyses are in the neighborhood, so to speak; e.g., D. Frede 2003 as an alternative to equating laws with lekta, the Kneales 1962 on absolute vs. relative necessity, Kneale 1938 for logical vs. metaphysical vs. empirical facts, necessity, LS as an alternative or addition to possible for vs. possible that, Rist 1969: 122, 132 for the role of natures in the Stoic retreat from necessity, Sorabji 1980 for his rejection of empirical vs. logical, and Stough 1978 for the room she finds in cannot for moral responsibility
} 
opportunity as opposed to intrinsic capacity, is to show that intuitions on both sides are not only correct but in fact complementary once we see that the Stoics recognized both: what I am calling metaphysical possibility, located in the intrinsic nature of each thing, and providential possibility, located in the chain of external causes.

With our central passage from Diogenes in mind, then, and in particular the interpretive question of what it means to be hindered externally to the concept, let's turn now to testimony from the late Stoic Epictetus. The following passage gives further reason to think the Stoics employed a notion of metaphysical possibility, and in particular that they thought of external hindrances this way.

D. Fittingly enough, the one thing the gods have placed in our power (eph' hemin epoiessan) is the one of supreme importance, the correct use of impressions. The other things they have not placed in our power. Is this because they didn't want to? My belief is that they would have entrusted them to us too, had they been able to, but that they simply weren't able. For we are on the Earth, bound by an Earthly body and Earthly partners. How then could we have failed to be hampered (empodizesthai) by externals with regard to these things? What does Zeus say? "Epictetus, if it had been possible, I would have made your wretched body and trappings free and unhindered. But as it is, please note, this body is not your own, but a subtle mixture of clay." 29

Here I take Epictetus to be expressing a sense of being hampered by externals that means being hampered by those things external to the mind that makes use of impressions, i.e., those things external to what is conceivable, or logically possible. In particular, we find that god is constrained by the matter he has to work with; being on Earth, bound by Earthly partners is to be bound by the properties of matter. Crucially, even god is subject to these constraints in crafting the cosmos: if it had been possible, I would have made your wretched body free and unhindered. Otherwise, the sphere of possibility would be constrained only by logical consistency; as it is, however, god is constrained by matter and so what is cosmically, or metaphysically possible is narrower than what is logically possible.

Thus, what is metaphysically possible is what is logically possible and not hindered externally to the concept by god's decisions within the given material constraints; and to define it this way, as what is not hindered, is of course to work around the external hindrances that there are. What is possible is what's left over after what is necessary (and thus impossible) has been established. According to this picture, then, god cannot make just any possible world - only those that can be crafted out of the matter he is given. Moreover, god does not make just any of those possible worlds, but rather the best one. ${ }^{30}$ God takes the matter, and crafts the best world he can; in so doing he establishes what is metaphysically necessary and possible. My next suggestion is that in addition to the various natures he creates within the constraints of matter, God establishes certain metaphysically necessary principles, most crucially the principle of bivalence and its correlate that there is no motion without a cause. ${ }^{31}$

Dorothea Frede has argued that the Stoics treated bivalence (future truth) not only as a consequence of Stoic fatalism (if everything is predetermined, then there must be future truths),

\footnotetext{
${ }^{29}$ Diss. 1.1.7-11 (62Kpart)

30 This claim is not to be confused with a teleological account of nature, it is rather a story of providential creation; cf. Hankinson 1999: 539 for agreement on "limitations on creative possibility supplied by material recalcitrance"

${ }^{31}$ Cicero, De Fato 20-1 (62G), Alexander, De Fato 185,7-11 (62H), 191,30-192,28 (55N)
} 
but also as an argument for it. ${ }^{32}$ If bivalence does not hold, the causal order of the cosmos is threatened: anything could happen at any time (as indeed the Epicureans held in introducing the swerve of an atom), contrary to Stoic determinism. Frede writes: "This coherence and stability can be maintained only if there is an eternal uninterrupted causal series. But not only that: there must be a fixed order within the causal series, and that can be guaranteed only if the same cause is always followed by the same effect. Take for example the rule: 'When someone puts a burning match to a dry haystack, the haystack will burn.' To guarantee the stability of the physical order the Stoics had to assume that there are such eternally valid causal principles that obtain even if nothing actually corresponds to the hypothetical state of affairs at a particular moment." Thus to question future truth, i.e., to consider suspending bivalence, is to question the very laws of nature; future truth is a necessary condition for causality.

For all that, however, it is perfectly conceivable, i.e., logically possible that bivalence does not hold and that the world is not determined - the Stoics were only too aware of this fact, surrounded as they were by lively criticism and debate over fatalism and future truth in a competitive intellectual era. Thus we wouldn't want to say that the principles and natures that god creates hold a priori as logically necessary. Rather, the necessity of metaphysical principles is a posteriori, according to the decisions god makes in crafting the cosmos within the constraints of matter. So, what is metaphysically possible is what is unhindered external to the concept, i.e., unhindered by the metaphysical principles and natures that god establishes. It is metaphysically possible for wood on the ocean floor to burn even if it will always be surrounded by water, because it remains combustible by nature.

We can also discern this gap between what is logically and metaphysically possible from the Stoic defense of infinite, extra-cosmic void. One of the many criticisms of the Stoic notion of void is that they cannot simultaneously say that the cosmos is at the center of void and yet claim that the void is isotropic. The Stoic response is that the cosmos is not in fact at the center of independently subsisting void, so they are not committed to an identifiable center of something infinite and isotropic. ${ }^{33}$ Nonetheless, they can speak as though there were such a middle, and even consider the possibility of a cosmos not at the center of void. Hence Plutarch quotes Chrysippus as saying that "if it [the cosmos] should be imagined elsewhere [than in the middle], destruction would almost certainly be attached to it;" and that "it has also in some such way been an accident of substance (ousia sunteteuchen), from the very fact that it is the kind of thing it is, to have occupied everlastingly the middle place, so that otherwise but also accidentally it does not admit of destruction." 34 In imagining the cosmos elsewhere, in a void that is in fact selfsubsistent, Chrysippus evinces a recognition that what is logically possible is distinct from what is metaphysically possible. It is also clear that substance (ousia), which for the Stoics picks out the material substrate, is what accounts for that distinction. ${ }^{35}$ Thus what is metaphysically possible is distinct from what is logically possible, as a function of god's decisions within the constraints of matter, establishing the principles, natures and causes of the one and only cosmos.

\footnotetext{
32 1990: 210; cf. Hankinson 1999: 519-20

33 As I argue in "How Nothing Can Be Something: The Stoic Theory of Void," forthcoming in Ancient Philosophy

34 Plut., St. rep. 1054C-D, trns. Cherniss; see also 1055D

35 That ousia refers to the material substrate is largely agreed, e.g., by LS, Sorabji, and Sedley; pace Menn
} 
What is metaphysically possible is also distinct from what is providentially possible, which captures the notion of possibility as opportunity that commentators have favored. In this sphere, as in the last, there are things that remain possible even though they are not and will not beherein lies moral responsibility. It is true enough that one cannot be held responsible for actions one did not have the opportunity to commit: a thief who never steals again because locked up is not thereby reformed and cannot be given credit for not stealing any more. Only if the opportunity to steal is presented and passed up can there be credit for not stealing. What is providentially possible is therefore what your circumstances allow, including the absence of ordinary hindrances like being locked up and what one might think of as technical hindrances like being too late, i.e., in the past. What is possible is thus what is not yet settled, what is possible prior to the external, initiating causes that set the principal cause in motion. It is thus providentially possible for the thief who is not locked up and has the opportunity to steal, not to steal, even if as a matter of fact he will.

On this basis even what is fated is not necessitated, and the Stoics can coherently stand by the third premise of the Master Argument, that there is a possible that neither is nor will be (at both the metaphysical and providential levels). Now, it's true that from the cosmic perspective what is providentially possible must in some sense be considered necessary, since it is impossible that the world order turn out otherwise. ${ }^{36}$ However, this cosmic perspective notwithstanding, there is an important difference between what is providentially possible and necessary. Namely, that what is providentially possible is not yet settled insofar as the relevant initiating causes that will set the principal cause in motion are not yet present to it; the rope has not yet unwound that far. Thus it is providentially possible that Socrates will escape from jail, until he drinks the hemlock - only then does his death become necessary (more on this below, with the Stoic account of necessity). ${ }^{37}$

In summary, I submit that Diogenes' definition of Stoic possibility in passage A should be understood as what admits of truth (logical possibility) and is not hindered externally to the concept, either as a matter of metaphysics (metaphysical possibility) or as a matter of external circumstances (providential possibility). The example Diogenes provides, "Diocles is alive" does not settle matters in one direction or the other. This proposition could be considered possible either as a matter of metaphysics: Dion is of an animate nature; or as a matter of providence: Dion is not dead (he either is or will be alive). Boethius' example is similarly neutral, and thus capable of illustrating both senses: "that I will reread Theocritus' Bucolica today." Our testimony is extremely compressed; although we cannot be certain, it is at least possible that these examples were carefully chosen to illustrate both kinds of possibility external to the concept that I describe.

$$
* * *
$$

Now I turn to Diogenes' definition of the impossible (A3): that which (a) does not admit of being true, <or (b) what does admit of being true but is opposed by things external to it from being true>, e.g., "Earth flies." Accepting Michael Frede's emendation (in brackets), this

\footnotetext{
${ }^{36}$ Cf. the Stoics' "bifocals" in Long 1971, also Rist 1969

${ }^{37}$ I take this to address Sorabji's concerns about responsibility amid necessity, since I deny that the chain of fate is necessary except once an event is past
} 
disjunctive definition is the contradictory of what is possible. ${ }^{38}$ It is ( $3 \mathrm{a}$ ) what is logically impossible, e.g., It is day and Not: it is day; or (3b) what is logically possible (i.e., internally consistent), but opposed externally. Again, we ask what it means to be opposed externally. Here the example, Earth flies, is of help, although intuitions do diverge. Bobzien takes the example to illustrate the first part of the definition, (2a), a logical impossibility. ${ }^{39}$ But the reason the Earth can't fly (as far as the Stoics are concerned) is that the Earth doesn't have wings. ${ }^{40}$ So I would argue that the reason Earth flies is impossible is that as a matter of metaphysical fact the Earth does not have wings and so cannot fly. It's at least conceivable that the Earth have wings, so it does not seem like a logical impossibility that is being illustrated. ${ }^{41}$ Further, it is clear that the relevant hindrance to Earth's flying is no external circumstance since there are no such circumstances for god, who is identical with everything there is. ${ }^{42}$ So the relevant impossibility must be metaphysical, and knowable only a posteriori, having established that as a matter of fact the Earth has no wings.

Now to Diogenes' definition of Stoic necessity, passage A4: (a) that which, being true, does not admit of being false, or (b) what on the one hand does admit of being false but is opposed by things external to it from being false, e.g., "Virtue benefits." It should be familiar by now that the first part of the definition (4a) corresponds to what is logically necessary, i.e., impossible not; and that the second part (4b) corresponds to what is metaphysically necessary. Here too scholars have thought that the example Virtue benefits illustrates a logical necessity for, as Martha Kneale puts it "a Stoic could scarcely have conceived that in certain circumstances 'Virtue is beneficial' might be false."43 Here again I would argue that while the Stoics are certainly committed to the necessity of this proposition, they would not have seen it as logically necessary. Following in the footsteps of Socrates, they would have been all too aware that few take this position to be true, let alone logically true, and concerned to argue for the necessity of this principle naturalistically. Indeed, it is uncharitable to think the Stoics would conflate their metaphysical principles with logical truths. Rather, Virtue benefits is necessarily true because our natures are such that virtue cannot fail to be good for us (the predicate is derived from the principal cause, as Reesor would put it); and it is not logically true since, as Glaucon so well illustrates in Plato's Republic, it is certainly conceivable that humans are pleonectic in nature so that justice is only instrumentally good, and never beneficial in itself.

The necessity of Stoic metaphysical principles and natures is confirmed by ample textual evidence. For instance, Alexander testifies that for the Stoics "What each does is in accordance with its proper nature ... Hence, they say, none of the things each of them does in accordance with its proper nature can be otherwise: everything they do is done of necessity ... For the stone,

\footnotetext{
38 With LS and Mignucci 1978, contra Inwood and Gerson1988; cf. earlier remarks concerning the conjunctive reading of possibility

39 1999: 118

${ }^{40}$ SE, PH 2.104-6 (35C3), M. 8.113

41 And to reply that it's logically impossible in the context of this wingless Earth that it fly, would be to concede the point that it's not true as a matter of logic that Earth doesn't fly

42 Plut., St. rep. 1050C-D (54T)

43 1962: 123; cf. Reesor 1978, Gourinat 2000: 206
} 
if released from a height, and not prevented, cannot fail to travel downwards." 44 Note here the idea that natures are as they are as a matter of necessity (as a function of its nature, the stone necessarily falls when unhindered by external circumstances), and that this corresponds to Reesor's first sense of fate as principal cause (and to the Philonian bare fitness extended to the second part of Stoic possibility). ${ }^{45}$ Alexander then adds: "the very fate, nature and rationale in accordance with which the all is governed is god. It is present in all things that exist and happen, and in this way uses the proper nature of all existing things for the government of the all."46 Having crafted the principles and natures that constitute fate in the first sense, god then relies on the necessity of their natures (uses the proper nature of all existing things) in unwinding the rope of fate by the chain of initiating causes.

The necessity of these natures is further emphasized when the Epicurean Philodemus tells us that for the Stoics the inference "Since the humans familiar to us are mortal in that and in so far as they are human, humans everywhere are mortal too" is correct (orthos). ${ }^{47}$ The reason the inference is correct is that the conditional "If something is human, then it is mortal" is sound, i.e., it meets the Stoic criterion of implication called cohesion, which says that "a conditional is sound whenever the contradictory of its consequent conflicts with its antecedent."48 Stoic implication is stronger than Philonian, which is merely truth-functional, and stronger again than Diodorian implication, which states that a conditional is sound when it is impossible for there to be a true antecedent and false consequent. But the criterion of Stoic implication is unclear to the extent that the nature of the conflict between affirmed antecedent and negated consequent is unclear.

It has been suggested by S. Sambursky and by M. Frede that we understand the conflict as logical, in contrast to empirical. ${ }^{49}$ Perhaps retreating from the force of logical necessity, Long \& Sedley suggest that the relevant sense of conflict is a conceptual rather than empirical incompatibility, such that "when the consequent is hypothetically eliminated the antecedent is thereby be 'co-eliminated' - a formulation which appears to outlaw any considerations which cannot be extracted from our understanding of the antecedent and consequent themselves." 50 I agree that the consequent and antecedent will be co-eliminated, but would like to bring a finer point to the discussion, because to say that the relevant necessity behind cohesion is conceptual rather than empirical cuts across elide the difference between logical and metaphysical necessity.

The example Sextus gives of a sound conditional according to the criterion of cohesion is If it is day, it is day, which is logically necessary and thus clearly knowable a priori. Certainly, analytic truths make for sound conditionals and that's why Sextus cites it as an example; but it's clear the Stoics don't want to restrict their inferences to logical or analytic truths. They are with Diodorus in aiming "to convert the sound conditional into the kind of necessary truth which might ground scientific or dialectical inferences." 51 Recognizing this, Long \& Sedley say it's our understanding of the antecedent and consequent themselves that makes the connection

\footnotetext{
44 De Fato, 181,18-27 (62G2-4); cf. Long 1970 for a detailed exegesis of Alexander's De Fato

${ }^{45} \mathrm{cf}$. Stough 1978: 223 about the necessity of acting according to our natures

46 192,25-28 (55N4)

47 Sign., fr. 6 (42G4)

${ }^{48} \mathrm{SE}, \mathrm{PH} 2.111$ (35B4); NB: sound for the Stoics, here, is captured by our true

491959 and 1974 respectively; see also Sorabji 1980: 267 on this

50 LS: 211

${ }^{51}$ LS: 210
} 
conceptual rather than empirical. Here I interject to suggest that the connection between antecedent and consequent is better thought of as metaphysical: necessary but a posteriori, and therefore already empirical, not logical. At the same time one wouldn't want to deny that there is a certain conceptual connection between antecedent and consequent in a sound conditional. What Earth is makes it metaphysically necessary that Earth does not fly, and our concepts are correspondingly related: the concept of Earth does not admit flying. Likewise, human nature makes it necessary that virtue is to our benefit, and this is reflected in our concepts so that it is scarcely conceivable that things be otherwise; nevertheless, no formal contradiction emerges from the supposition. ${ }^{52}$

In case doubts remain that these necessary truths are a posteriori and conceivably otherwise, I offer this additional evidence that shows even such correlative concepts as good and evil, justice and injustice, pain and pleasure, virtue and vice, and even true and false are a posterior in the way I have been describing, as a function of material constraints and god's decisions for the best.

E. In his judgment it was not nature's principal intention to make people liable to disease: that would not have been fitting for nature, the creator and mother of all good things. But, he [Chrysippus] adds, while she was bringing about many great works and perfecting their fitness and utility, many disadvantageous things accrued as inseparable from her actual products. These, he says, were created in accordance with nature, but through certain necessary 'concomitances' (which he calls kata parakolouthēsin). Just as, he says, when nature was creating people's bodies, it was required for the enhancement of our rationality and for the very utility of the product that she should construct the head of very thin and tiny portions of bone, but this utility in the principal enterprise has as a further, extraneous consequence the inconvenience that the head became thinly protected and fragile to small blows and knocks - so too, illnesses and diseases were created while health was being created. ${ }^{53}$

It is clear that the necessity of illness alongside health is not a logical necessity, since nature would have preferred to do otherwise, and thus can at least conceive of health without illness. It is also clear that the concomitances result from material constraints, and that the relevant necessity in play is material necessity. Even such correlative concepts as good and evil, health and illness, virtue and vice are connected conceptually only because they are connected metaphysically, as a function of matter; and such necessity is entirely a posteriori.

Thus I suggest that what underwrites the Stoic criterion of cohesion is not logical but metaphysical necessity; and although it is inconceivable that necessary truths fail to hold, it is perfectly conceivable that what is metaphysically necessary be otherwise. This is why the Mowing Argument is invalid: 1) if you will mow, you will mow; and, if you will not mow, you will not mow; 2) but necessarily, either you will mow or you will not mow; 3) therefore if you will mow, you will mow necessarily; and, if you will not mow, it is impossible that you mow; the contingent is eliminated. ${ }^{54}$ The principle of bivalence expressed in premise 2 is itself metaphysically necessary, but the proposition that must now be true or false according that principle, as expressed in premise 3 , is not itself necessary or impossible; it is merely predetermined, as expressed in premise 1.

\footnotetext{
${ }^{52}$ Cf. Martha Kneale 1938, for whom what is metaphysically necessary is that whose consequent is inconceivable but not self-contradictory

${ }^{53}$ Gellius 7.1.1-13 (54Q); examples cited in introducing the text occur earlier in the passage, not quoted here, but subject to the same account

${ }^{54}$ Ammonius, In Ar. De int. 131,20-32 (28G)
} 
We can now see why the Stoics retain the Philonian conditional (material implication), which they express as a negated conjunction, Not both: $p$ and not- $q$. Philonian implication expresses what is true as a matter of fate, i.e., what is determined (and thus subject to divination) but not, for all that, necessary. As Long \& Sedley observe, a negated conjunction asserts no direct logical connection between $p$ and $q$, and "since laws of divination assert empirical rather than logical connections between past and future truths, the negated conjunction is indeed the appropriate means of formulating them." 55 Here again I interject to suggest we say instead that the laws of divination assert providential rather than metaphysical connections - what is determined rather than necessitated. This is why the Stoics can maintain that what is determined not to be, is nonetheless possible: no necessity attaches to the future truth, which is reflected in the use of the conjunction to express future truths (while the conditional is reserved for metaphysical and logical truths that do hold of necessity). Future truths are providentially possible, not necessary. Thus the Stoics avoid the charge that appeared above in passage B (Cicero's testimony with the jewel), that bivalence commits them to false futures as impossible, and true futures as necessary. ${ }^{56}$

This leaves open the question, what is providential necessity? One might still worry, as I did above, that entire world order is providentially necessary, since it cannot turn out otherwise. But providential necessity is not just the ineluctable hand of fate. Rather, it corresponds to what is already settled, how far the rope has unwound. Alexander again:

F. Whenever the external causes that encourage the stone's natural motion are also present, the stone of necessity moves with its natural motion. And these causes of its moving are, at the time, unconditionally and necessarily present. Not only is it incapable of not moving when they are present, but it also moves of necessity at that time, and such a movement is brought about by fate through the stone. ${ }^{57}$

This passage expresses two levels of necessity: the metaphysical necessity that the stone act according to its nature upon encountering the relevant external causes (that the stone will fall if dropped), and the providential necessity of the moving causes once they are present or actual (the providential necessity of the stone's falling when dropped). Hence, the stone is counterfactually incapable of not falling when dropped (due to the metaphysical necessity of its nature), and actually incapable of not moving once it is in fact dropped (due to the providential necessity of what is current or past). Once the stone is dropped, it is providentially necessary, i.e., settled, that it falls. Until then it is merely possible, albeit predetermined. Hankinson says something similar: "Consider an example of Aristotle's: a new cloak might perish as a result of ordinary wear, or it might be cut. For the Stoics, sub specie aeternitatis there is only one thing that can happen to it - the unraveling of fate will see to that. However, there is nothing now in the world that prevents either outcome, for no causally efficient state of affairs is now making it the case that it will (or will not) be cut." 58 What is providentially necessary is what a causally efficient state of affairs makes to be the case, what is happening now and what has been. ${ }^{59}$

\footnotetext{
55236

${ }^{56}$ Cf. Bobzien 1993: 82 for a denial that future truths are contingent, Reesor 1978 and Rist 1969 for an endorsement

57 181,28-30 (62G4, part)

58 1999: 528

59 Thus it is clear how Chrysippus can affirm the first premise of the Master Argument, that all past truths are necessary. Although Cleanthes denies this premise, we need not take this as a deep divide in Stoic modal theory (as,
} 
Finally, I turn to Diogenes' definition of what is not necessary: that which both is true and can be false, being opposed by nothing external, e.g., "Dion is walking." Here again the central interpretive question concerns what it means to be opposed externally. As with the case of "Diocles is alive" to illustrate possibility I suggest that we hear the example as illustrating what is not necessary either as a matter of metaphysics or as a matter of providence. Dion's nature does not dictate that he be walking all the time (the way, say, fish nature might dictate that Nemo be swimming all the time), nor do his life circumstances dictate that he walk all the time. Note that even if Dion's fate were to spend his whole life walking, it would not thereby be providentially necessary that he walk. This was the point of making the distinction between what is providentially possible and necessary: namely, to preserve contingency even for future truths. Thus even if as a matter of fate Dion is walking were always true (while he lives), it will not be a future truth expressible by a sound conditional (since that is reserved for logical and metaphysical truths) but by the negated conjunction: Not: Dion lives and Not: Dion walks. What is not necessary is thus the sphere of things that can be otherwise, either as a matter of metaphysics or providence.

In conclusion, if I am right that the Stoics recognized these three senses of necessity and possibility, the Stoic retreat from necessity is accomplished across logic, physics and ethics. In the domain of logic, we see that the Stoic response to the Master Argument is underwritten by the fact that providential necessity applies only to present and past truths, so future truth and contingency are compatible. Also, that we have reason to see metaphysical necessity as the principle of cohesion. In physics we see that metaphysical necessity underwrites the counterfactual truths that guarantee the stability of the cosmos. And in ethics, the sphere of responsibility is secured by what is providentially possible. Thus the Stoics embrace the apparent paradox of future truth and contingency without falling into contradiction.

e.g., Rist 1969: 118, 1978: 197, Barreau 1976: 30-40). Cleanthes could deny that past truths are necessary in the sense that they remain contingent events, not metaphysically necessary. It would then be open for him to embrace past events as providentially necessary, along with Chrysippus, while denying they are metaphysically necessary in a way that meets the dialectical requirements of the Master Argument. Alternatively, Cleanthes could deny providential necessity altogether, holding that fate is always determined but never necessary, so even past events do not become necessary; he could argue from everlasting recurrence that past contingents are future contingents, and thus never necessary. Both of these, however, constitute a legitimate retreat from necessity, obviating the need to see possibility as merely epistemic, on which see Long 1971: 189, Reesor 1978: 194-197, Sorabji 1980: 276-278 


\section{Necessity, Possibility and Determinism in Stoic Thought Vanessa de Harven}

\section{Bibliography}

von Arnim, Johannes. Stoicorum Veterum Fragmenta, Vols. I-IV. B.G. Teubner. 1902.

Barreau, Hervé. "Cléanthe et Chrysippe face au maitre-argument de Diodore." Stoic. Log 1976. $20-41$.

Bobzien, Susanne. "Chrysippus' modal logic and its relation to Philo and Diodorus." 1993. - "Logic: The Megarics, The Stoics" in eds. K. ALgra, J. Barnes. J. Mansfeld, M. Schofield. The Cambridge History of Hellenistic Philosophy. Cambridge University Press. 1999. 83-157. — "Stoic Logic" in ed. B. Inwood The Cambridge Companion to the Stoics. Cambridge University Press. 2003. 85-123.

Bochenski, Joseph M. "Ancient formal logic." North-Holland Publishing Company. 1951.

Denyer, Nicholas. "Time and modality in Diodorus Cronus." Theoria 47.1. 1981. 31-53.

Frede, Dorothea. "Fatalism and Future Truth." Proceedings of the Boston Area Colloquium in Ancient Philosophy 6. 1990. 195-227.

— "Stoic Determinism" in ed. B. Inwood The Cambridge Companion to the Stoics. Cambridge University Press. 2003. 179-205.

Frede, Michael. Die stoische Logik. Vandenhoeck und Ruprecht, 1974.

Gourinat, Jean-Baptiste. La Dialectique des Stoïciens. Vrin. 2000.

Hankinson, Robert. "Determinism and Indeterminism" in eds. K. ALgra, J. Barnes. J. Mansfeld, M. Schofield. The Cambridge History of Hellenistic Philosophy. Cambridge University Press. 1999. 513541.

de Harven, Vanessa. "How Nothing Can Be Something." Ancient Philosophy. Forthcoming.

Inwood, Brad and Gerson, L. P. Hellenistic Philosophy, Introductory Readings. Hackett. 1988. 1997.

Kneale, Martha. "Logical and metaphysical necessity." Proceedings of the Aristotelian Society. Harrison \& Sons, Ltd., 1937. 253-268.

Kneale, William and Martha. The Development of Logic. Oxford University Press. 1962.

Kripke, Saul. Naming and Necessity. Harvard University Press. 1972, 1980. 
Long, A. A. "Stoic determinism and Alexander of Aphrodisias De Fato (i-xiv)." Archiv für Geschichte der Philosophie 52.3. 1970. 247-268.

— "Freedom and Determinism in the Stoic Theory of Human Action." Problems in Stoicism. The Athlone Press. 1971. 173-199.

Long, A. A. and Sedley, David. The Hellenistic Philosophers. Cambridge University Press. 1987.

Mates, Benson. Stoic Logic. University of California Press. 1953.

Mignucci, Mario. "Sur La Logique Modale des Stoïciens" in ed. J. Brunschwig Les Stö̈ciens et Leur Logique. Vrin. 1978. 303-332.

Prior, Arthur N. "Diodoran modalities." The Philosophical Quarterly 5.20. 1955. 205-213.

Reesor, Margaret. "Fate and Possibility in Early Stoic Philosophy." Phoenix 19.4. 1965. 285-297. - "Necessity and Fate in Stoic Philosophy" in ed. John M. Rist. The Stoics. University of California Press. 1978. 187-202.

Rist, John M. "Fate and Necessity" in ed. John M. Rist. Stoic Philosophy. Cambridge University Press. 112-132.

Sambursky, Samuel. Physics of the Stoics. Princeton University Press. 1959.

Sharples, R. W. Alexander of Aphrodisias on Fate. Duckworth. 1983.

Sorabji, Richard. "Causation, Laws, and Necessity" in eds. M. Schofield, M. Burnyeat, J. Barnes. Doubt and Dogmatism. Clarendon Press. 1980

Striker, Gisela. "Origins of the concept of natural law." Proceedings of the Boston Area Colloquium in Ancient Philosophy. 2. 1987. 79-94.

Stough, Charlotte. "Stoic Determinism and Moral Responsibility." Ed. John M. Rist The Stoics. University of California Press. 1978. 203-232. 